Article

\title{
Hippocampal Expression of Cytochrome P450 1B1 in Penetrating Traumatic Brain Injury
}

\author{
Erik Lidin ${ }^{1, *} \mathbb{C}$, Mattias K. Sköld ${ }^{1,2} \mathbb{0}$, Maria Angéria ${ }^{1}$, Johan Davidsson ${ }^{3} \mathbb{D}$ and Mårten Risling ${ }^{1}$ \\ 1 Experimental Traumatology Unit, Department of Neuroscience, Karolinska Institute, \\ 17177 Stockholm, Sweden; mattias.skold@ki.se (M.K.S.); maria.angeria@ki.se (M.A.); \\ Marten.Risling@ki.se (M.R.) \\ 2 Section of Neurosurgery, Department of Neuroscience, Uppsala University, 75185 Uppsala, Sweden \\ 3 Department of Mechanics and Maritime Sciences, Chalmers University of Technology, \\ 41296 Gothenburg, Sweden; johan.davidsson@chalmers.se \\ * Correspondence: erik.lidin@ki.se; Tel.: +46-735-207-598
}

check for updates

Citation: Lidin, E.; Sköld, M.K.; Angéria, M.; Davidsson, J.; Risling, M. Hippocampal Expression of Cytochrome P450 1B1 in Penetrating Traumatic Brain Injury. Int. J. Mol. Sci. 2022, 23, 722. https://doi.org/ $10.3390 /$ ijms23020722

Academic Editor: Anna-Leena Sirén

Received: 21 December 2021

Accepted: 8 January 2022

Published: 10 January 2022

Publisher's Note: MDPI stays neutral with regard to jurisdictional claims in published maps and institutional affiliations.

Copyright: (C) 2022 by the authors. Licensee MDPI, Basel, Switzerland. This article is an open access article distributed under the terms and conditions of the Creative Commons Attribution (CC BY) license (https:// creativecommons.org/licenses/by/ $4.0 /)$.

\begin{abstract}
Hippocampal dysfunction contributes to multiple traumatic brain injury sequala. Female rodents' outcome is superior to male which has been ascribed the neuroprotective sex hormones $17 \beta$ estradiol and progesterone. Cytochrome P450 1B1 (CYP1B1) is an oxidative enzyme influencing the neuroinflammatory response by creating inflammatory mediators and metabolizing neuroprotective $17 \beta$-estradiol and progesterone. In this study, we aimed to describe hippocampal CYP1B1 mRNA expression, protein presence of CYP1B1 and its key redox partner Cytochrome P450 reductase (CPR) in both sexes, as well as the effect of penetrating traumatic brain injury (pTBI). A total 64 adult Sprague Dawley rats divided by sex received pTBI or sham-surgery and were assigned survival times of 1-, 3-, 5- or 7 days. CYP1B1 mRNA was quantified using in-situ hybridization and immunohistochemistry performed to verify protein colocalization. CYP1B1 mRNA expression was present in all subregions but greatest in CA2 irrespective of sex, survival time or intervention. At 3-, 5- and 7 days post-injury, expression in CA2 was reduced in male rats subjected to pTBI compared to sham-surgery. Females subjected to pTBI instead exhibited increased expression in all CA subregions 3 days post-injury, the only time point expression in CA2 was greater in females than in males. Immunohistochemical analysis confirmed neuronal CYP1B1 protein in all hippocampal subregions, while CPR was limited to CA1 and CA2. CYP1B1 mRNA is constitutively expressed in both sexes. In response to pTBI, females displayed a more urgent but brief regulatory response than males. This indicates there may be sex-dependent differences in CYP1B1 activity, possibly influencing inflammation and neuroprotection in $\mathrm{PTBI}$.
\end{abstract}

Keywords: traumatic brain injury; sex differences; cytochrome P450 1B1; hippocampus

\section{Introduction}

Secondary injuries of traumatic brain injury (TBI) are initiated by biochemical changes that occur directly after primary injury [1] and are essential to manage for reduction of injury sequala. However, despite recent progress in the comprehension of the complex cascade of molecular events characterizing the secondary injury, there are no therapeutic agents available [2].

In a previous publication we showed regulation of genes including the Cytochrome P450 family in hippocampus and cortex after penetrating traumatic brain injury (pTBI) in rats [3], further analysis of that material showed Cytochrome P450 1B1 (CYP1B1) to be distinctly upregulated. Data extracted from this gene array material regarding the Cytochrome P450 family are presented in the Appendix A (Table A1).

CYP1B1 is a fundamental enzyme in both humans and rodents, influencing metabolic and inflammatory pathways as well as metabolizing multiple xenobiotics [4,5]. CYP1B1 metabolizes arachidonic acid (AA) to hydroxyeicosatetraenoic acids (HETEs), a group of 
inflammatory mediators that generate reactive oxygen species and activate apoptotic pathways [6,7]. Furthermore, CYP1B1 is a key extrahepatic metabolizer of neuroprotective $17 \beta$-estradiol (E2) [8]. E2 is a potent neuroinflammatory mediator, administration of E2 in male and ovariectomized female mice exposed to TBI reduces infarction size, edema and hippocampal apoptosis and improves outcome [9-11]. CYP1B1 also metabolizes progesterone, that has multifactorial neuroprotective properties that effect excitotoxicity, cerebral edema, and inflammatory cytokines [4,12]. However, evidence of both positive and negative effects of altered CYP1B1 protein levels or its products exist, suggesting that CYP1B1 acts on both beneficial and deleterious pathways $[4,5,13,14]$. CYP1B1 activity directly correlates to its essential electron donor Cytochrome P450 reductase (CPR), and deletion of this key redox partner results in loss of practically all CYP1B1 function $[15,16]$.

Experimental rodent models have highlighted the importance of sex when studying TBI, as female rodents have a lower mortality when exposed to TBI [10]. Additionally, female rodents also exhibit reduced lesion area, cerebral edema, and cell death [17-19]. However, indications of sex-dependent differences and a beneficial effect of female sex hormones in rodent TBI models do not align with epidemiological studies of TBI in humans, where results are ambiguous [20-23].

Hippocampal pathology is central in several TBI sequala such as sleep disorder, cognitive disability, and memory impairment. The hippocampus consists of distinct subregions with unique intrinsic and extrinsic connections [24]. Cellular subpopulations within each subregion exhibit differences regarding circuity, gene expression as well as both electrophysiological and functional properties $[25,26]$.

We have developed a model utilizing a high probe velocity and shape to simulate a clinically plausible pTBI [27-29]. CYP1B1 is believed to impact multiple molecules part of the secondary injury of pTBI, by producing inflammatory mediators HETEs $[6,7]$ and metabolizing neuroprotective E2 and progesterone [4,5]. No previous studies have studied hippocampal CYP1B1 mRNA expression in the context of TBI or sex. In this pilot study, we therefore aim to map the presence of hippocampal CYP1B1 in male and female rats. Furthermore, we aim to study the effect of pTBI on CYP1B1 mRNA expression and if indications of sex-dependent differences after injury exist.

\section{Results}

Due to the nature of this explorative pilot study, with multiple small groups aimed at providing information for future studies, groups are underpowered and statistical conclusions should be drawn with caution. Results indicating changes in expression following PTBI and sex-dependent differences are preliminary indications until confirmed by future studies with greater power.

\subsection{In Situ Hybridization}

In-situ hybridization detected CYP1B1 mRNA in all five hippocampal subregions. However, interregional differences were observed. Irrespective of sex, intervention, and survival time, CYP1B1 mRNA was highest in CA2 and lowest in DG. Quantification and analysis were performed on results from RNAscope and ViewRNA was used as a control to confirm our findings. The same pattern of expression was observed using both RNAscope and ViewRNA (Figure 1).

In response to pTBI, all subregions exhibited altered CYP1B1 mRNA expression at some point. Both males and females subjected to pTBI exhibited an increased CYP1B1 mRNA expression in CA1 1 day post-injury (dpi) (Figure 2a,b). Unlike males, females subjected to $\mathrm{pTBI}$ had reduced expression in CA2 $1 \mathrm{dpi}$ compared to sham (Figure 2a,b). Females subjected to pTBI exhibited increased expression in all subregions compared to sham $3 \mathrm{dpi}$ (Figure 2c). In contrast, males subjected to pTBI exhibited reduced expression in CA2 and CA4 3 dpi (Figure 2d). The increased expression observed in females with pTBI 3 dpi was reversed $5 \mathrm{dpi}$, and expression in CA1, CA2 and CA3 was lower than in sham counterparts (Figure 2e). $5 \mathrm{dpi}$, expression was significantly lower in males subjected to pTBI compared 
to sham-surgery in both CA2 ( $p=0.0349)$ and DG ( $p=0.0222)$ (Figure 2f). In females $5 \mathrm{dpi}$, significant reduction in the group receiving pTBI was only observed in DG $(p=0.0264)$ (Figure 2e). In males $7 \mathrm{dpi}$, expression in CA2 and CA3 was reduced in those subjected to pTBI compared to sham (Figure $2 \mathrm{~h}$ ). In females $7 \mathrm{dpi}$, no such decrease was observed and expression in those subjected to pTBI was increased in CA4 compared to sham (Figure $2 \mathrm{~g}$ ).

Sex-dependent differences in CYP1B1 mRNA expression were observed in rats subjected to sham-surgery. Expression in CA2 was higher in males compared to females at every time point studied (Figure 3). Similarly, expression in CA4 was higher in males 3, 5 and 7 dpi (Figure 3). Sex-dependent differences were also present in rats subjected to pTBI, where males exhibited higher expression in CA1 and CA2 compared to females $1 \mathrm{dpi}$ (Figure 3b). In contrast, expression in females was higher in every subregion when compared to males $3 \mathrm{dpi}$ (Figure $3 \mathrm{~d}$ ). The opposite was true when comparing expression $7 \mathrm{dpi}$, where expression in males was higher in every subregion compared to females (Figure 3h).

We observed differences in the temporal pattern of CYP1B1 mRNA expression. CA2 expression was lower in the females subjected to sham-surgery $7 \mathrm{dpi}$ compared to 1, 3 and 5 dpi. Furthermore, an increase of expression occurred in CA4 3 dpi (Figure 4a). Temporal differences in expression among males subjected to sham-surgery were apparent. In CA2 and CA3 expression gradually increased and reached peak-expression after 5 and $7 \mathrm{dpi}$, respectively (Figure $4 \mathrm{~b}$ ). In CA4, lower expression was observed $1 \mathrm{dpi}$ compared to other survival times (Figure $4 \mathrm{~b}$ ).

Temporal changes were greater in rats subjected to pTBI. In females, every subregion exhibited the same pattern of temporal changes, however the quantified levels differed. CYP1B1 mRNA expression was low $1 \mathrm{dpi}$ but increased and reached peak-expression $3 \mathrm{dpi}$ (Figure 4c). No apparent pattern of expression was observed in males, where CA1 and CA2 reached peak expression $1 \mathrm{dpi}$, followed by a sharp decline of expression $3 \mathrm{dpi}$ (Figure $4 \mathrm{~d}$ ). Peak expressions in CA3 and CA4 were instead reached 7 dpi (Figure $4 d$ ). Similar to the temporal pattern of expression observed in females, every subregion examined in males had a higher expression 7 dpi than 5 dpi (Figure $4 \mathrm{~d}$ ).

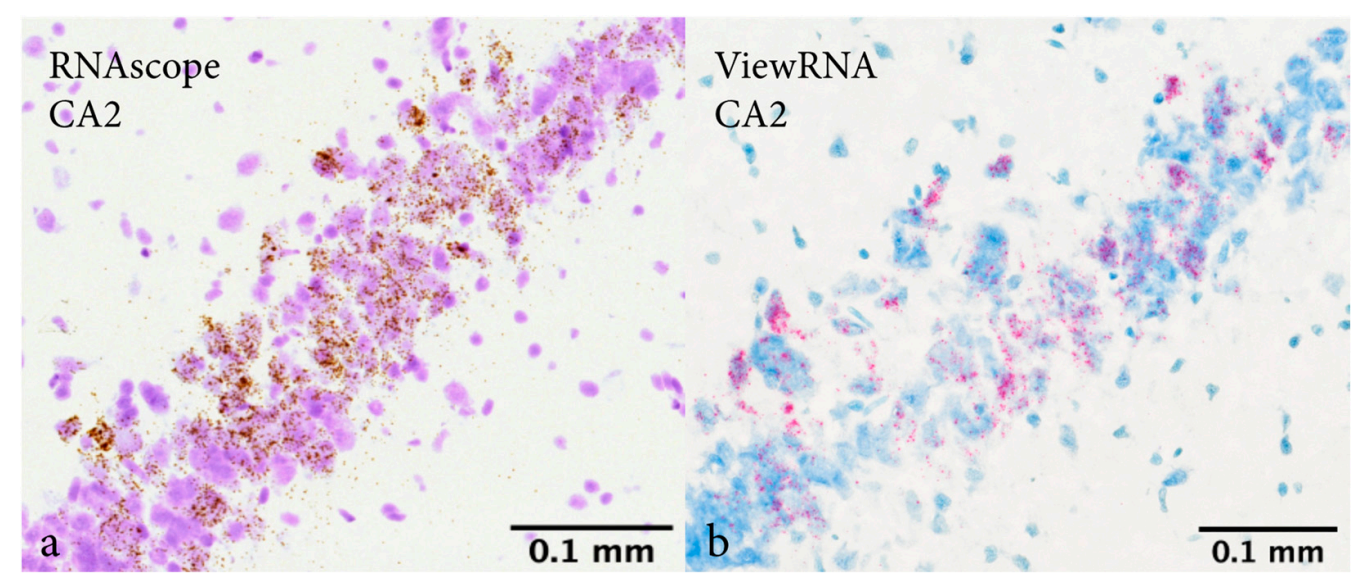

Figure 1. Representative images from ipsilateral subregion CA2 using RNAscope and ViewRNA. Images captured at $20 \times$ magnification from the same female rat subjected to penetrating traumatic brain injury and a survival time of 3 days. Captured at Bregma: $-3.84 \mathrm{~mm}$. Image (a) shows CYP1B1 mRNA marked in brown (RNAscope) and a cresyl violet counterstaining. Image (b) shows CYP1B1 mRNA marked in red (ViewRNA) and a methyl green counterstain. Expression was greatest in CA2 irrespective of sex, intervention and survival time using both RNAscope (a) and ViewRNA (b). Abbreviations: CA2: Cornu Ammonis 2. 
Female

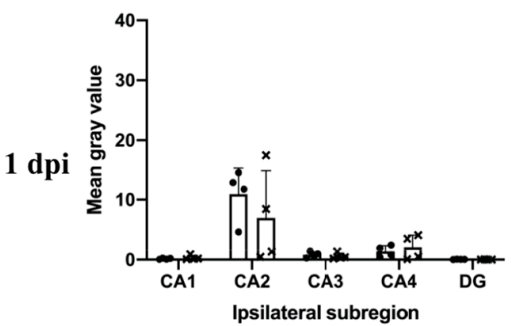

a



c

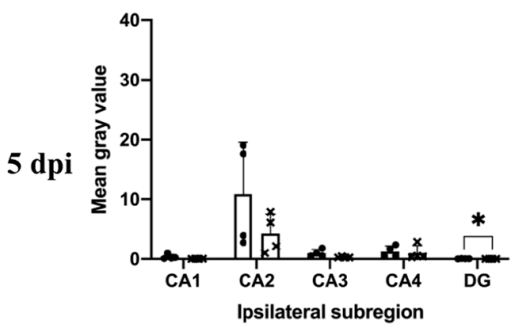

e

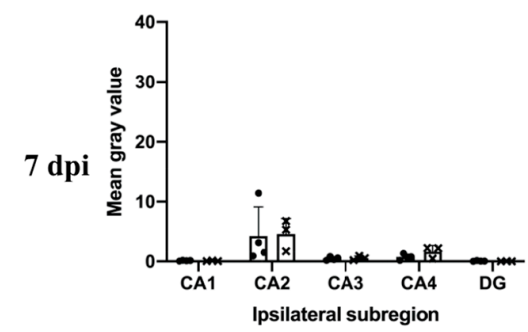

g

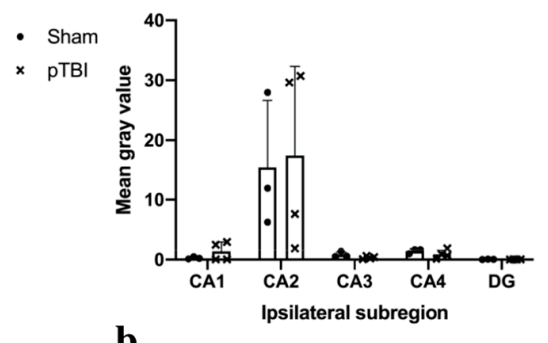

b

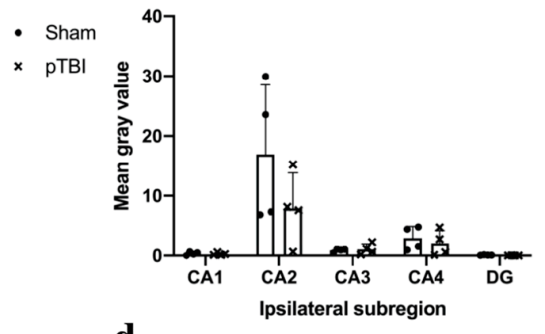

d

- Sham

$\times$ pTBI

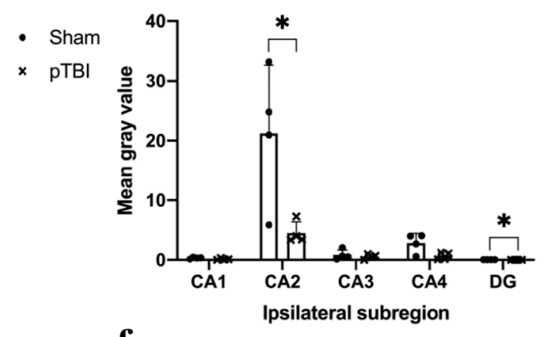

f

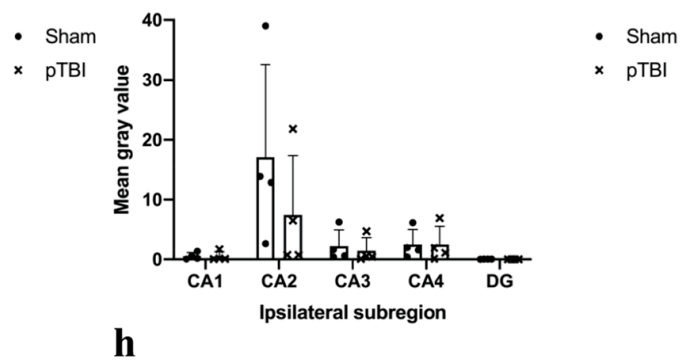

Figure 2. Comparison of hippocampal CYP1B1 mRNA expression detected by in situ hybridization in rats subjected to either sham-surgery or pTBI. Animals in Sham received a craniotomy, while animals in pTBI received a craniotomy with a subsequent pTBI. CYP1B1 mRNA was detected by in situ hybridization. Comparisons between Sham and pTBI were performed in animals with the same sex and survival time. Graphs show female mRNA expression $1 \mathrm{dpi}(\mathbf{a})$, male mRNA expression 1 dpi (b), female mRNA expression 3 dpi (c), male mRNA expression 3 dpi (d), female mRNA expression 5 dpi (e), male mRNA expression 5 dpi (f), female mRNA expression 7 dpi (g), male mRNA expression $7 \mathrm{dpi}(\mathbf{h})$. The mean gray value is presented in the Y-axis, showing the average mean gray value calculated from each measured cell for each subregion. To calculate mean gray value, images were made binary and in-situ probes made black and separated from the white background. The gray value of the color black was set to 255 and the value for white to 0 . The gray value of each cell 
is therefore a measurement of the area of cell marked by the in-situ probe. The gray values from each cell of each subregion were then used to calculate the mean gray value of each subregion and animal. The X-axis shows the ipsilateral subregions analyzed. Quantified CYP1B1 mRNA was highest in subregion CA2 irrespective of sex, intervention, and survival time (a-h). $5 \mathrm{dpi}$, males subjected to pTBI exhibited significantly lower expression compared to sham in subregions CA2 $(p=0.0349)$ and DG ( $p=0.0222)(\mathbf{f})$. In females $5 \mathrm{dpi}$, expression in DG was significantly lower in those subjected to pTBI compared to sham-surgery $(p=0.0264)(\mathbf{e})$. The values are presented as mean + SD for each group, including the mean for each animal. Horizontal bars marked with "*" show differences where $p<0.05$. Abbreviations: CA: Cornu Ammonis, CYP1B1: Cytochrome P450 1B1, DG: Dentate gyrus, dpi: days post-injury, pTBI: penetrating traumatic brain injury.

\section{Sham}

\section{pTBI}



a

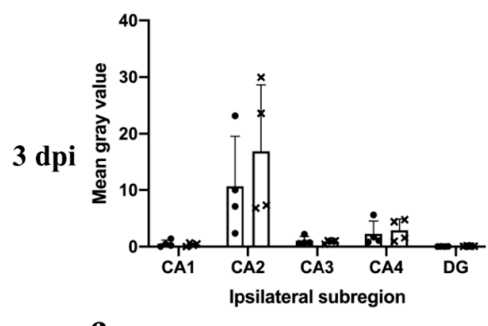

c

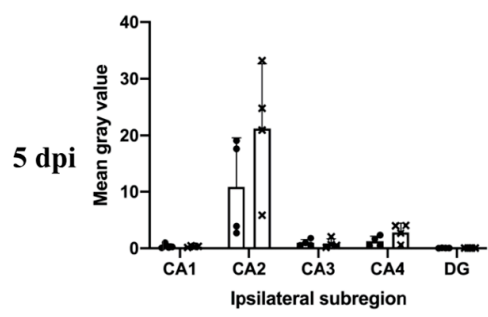

e

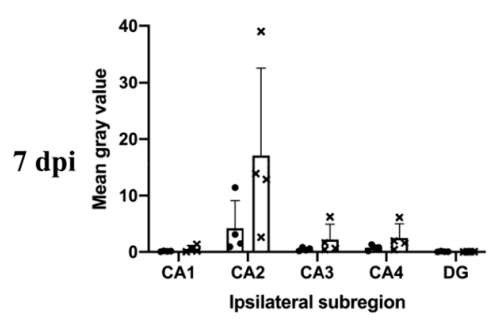

g
- Female

$\times$ Male

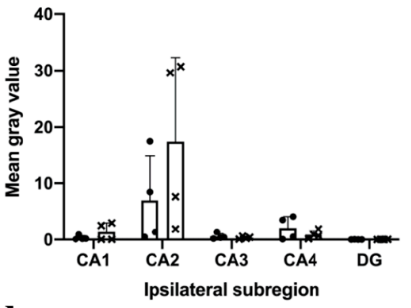

b

- Female
$\times$ Male



d

- Female
$\times$ Male

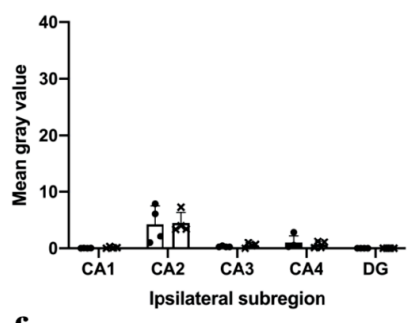

f
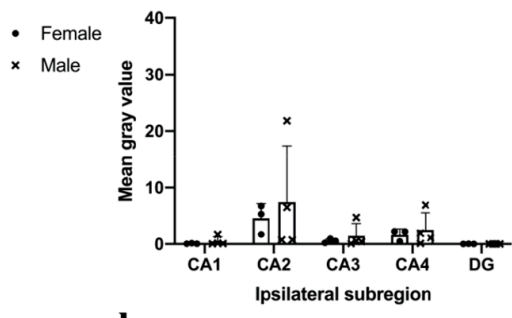

- Female

$\times$ Male

- Female

$\times$ Male

- Female

$\times$ Male

h

- Female

$\times$ Male

Figure 3. Comparison of male and female hippocampal CYP1B1 mRNA expression in rats subjected to either sham-surgery or pTBI. Animals in Sham received a craniotomy, while animals in pTBI received a craniotomy with a subsequent pTBI. Graphs show mRNA expression $1 \mathrm{dpi}$ in males and females subjected to sham-surgery (a), mRNA expression $1 \mathrm{dpi}$ in males and females subjected to 
pTBI (b), mRNA expression 3 dpi in males and females subjected to sham-surgery (c), mRNA expression $3 \mathrm{dpi}$ in males and females subjected to pTBI (d), mRNA expression 5 dpi in males and females subjected to sham-surgery (e), mRNA expression 5 dpi in males and females subjected to pTBI (f), mRNA expression $7 \mathrm{dpi}$ in males and females subjected to sham-surgery (g), mRNA expression 7 dpi in males and females subjected to pTBI (h). CYP1B1 mRNA was detected by in situ hybridization. The mean gray value is presented in the Y-axis, showing the average mean gray area calculated from each measured cell for each subregion. To calculate mean gray value, images were made binary and in-situ probes made black and separated from the white background. The gray value of the color black was set to 255 and the value for white to 0 . The gray value of each cell is therefore a measurement of the area of cell marked by the in-situ probe. The gray values from each cell of each subregion were then used to calculate the mean gray value of each subregion and animal. The $\mathrm{X}$-axis shows the ipsilateral subregions analyzed. Females subjected to pTBI and a 3 day survival time exhibited higher CYP1B1 mRNA expression in every CA-subregion compared to their male counterparts (d). The values are presented as mean + SD for each group, including the mean for each animal. Abbreviations: CA: Cornu Ammonis, CYP1B1: Cytochrome P450 1B1, DG: Dentate gyrus, dpi: days post-injury, pTBI: penetrating traumatic brain injury.

Female



a

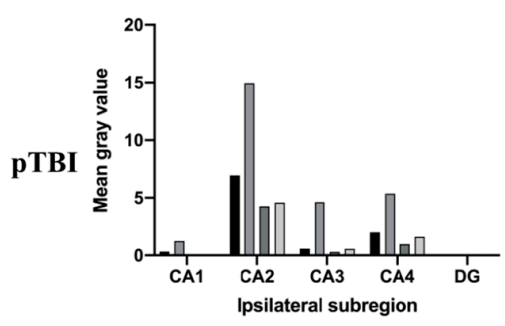

c

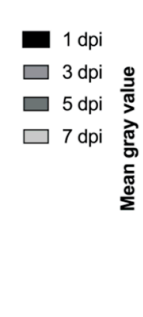

b
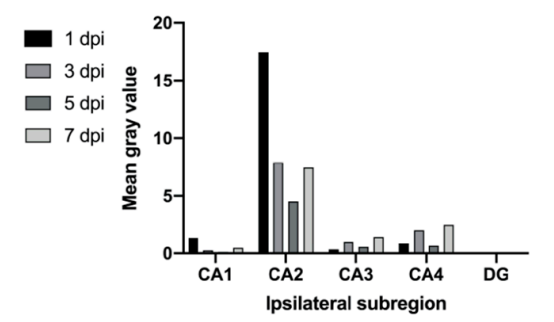

d
Male
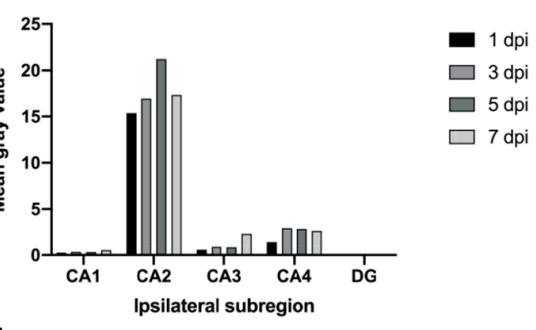

$\square 5 \mathrm{dpi}$

$\square 7 \mathrm{dpi}$

Figure 4. Overview of temporal changes in male and female hippocampal CYP1B1 mRNA expression in rats subjected to either sham-surgery or pTBI. Animals in Sham received a craniotomy, while animals in pTBI received a craniotomy with a subsequent pTBI. Survival times analyzed were 1-, 3-, 5- and 7 days. Graphs show timeline over CYP1B1 mRNA expression in females subjected to sham-surgery (a), males subjected to sham-surgery (b), females subjected to pTBI (c), males subjected to PTBI (d). CYP1B1 mRNA was detected by in situ hybridization. The mean gray value is presented in the Y-axis, showing the average mean gray area calculated from each measured cell for each subregion. To calculate mean gray value, images were made binary and in-situ probes made black and separated from the white background. The gray value of the color black was set to 255 and the value for white to 0 . The gray value of each cell is therefore a measurement of the area of cell marked by the in-situ probe. The gray values from each cell of each subregion were then used to calculate the mean gray value of each subregion. The $\mathrm{X}$-axis shows the ipsilateral subregions analyzed. In animals receiving pTBI, CYP1B1 mRNA expression is highest $1 \mathrm{dpi}$ in males (d), whilst the highest expression in females is reached $3 \mathrm{dpi}(\mathbf{c})$. The values are presented as means. Individual values and SD-values are presented in Figures 2, 3 and 5. Abbreviations: CA: Cornu Ammonis, CYP1B1: Cytochrome P450 1B1, DG: Dentate gyrus, dpi: days post-injury, pTBI: penetrating traumatic brain injury. 
Focusing on the subregion with the highest CYP1B1 mRNA expression, CA2, the response to pTBI differs between the sexes. In females subjected to pTBI, expression was lower than in females receiving sham-surgery $1 \mathrm{dpi}$, whilst no similar difference was observed in males (Figure 5). At 3 dpi, females subjected to pTBI exhibited higher expression than those receiving sham-surgery, while the opposite was true for males (Figure 5). Both sexes exhibited lower expression in the group receiving pTBI compared to those receiving sham-surgery $5 \mathrm{dpi}$, but this difference was only significant in males $(p=0.0349)$ (Figure 5). Males subjected to pTBI still had a lower expression compared to those receiving sham-surgery $7 \mathrm{dpi}$, whilst this difference was non-existent in females (Figure 5).

Female

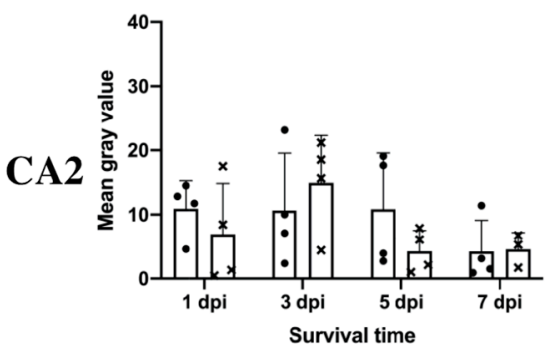

$\mathbf{a}$

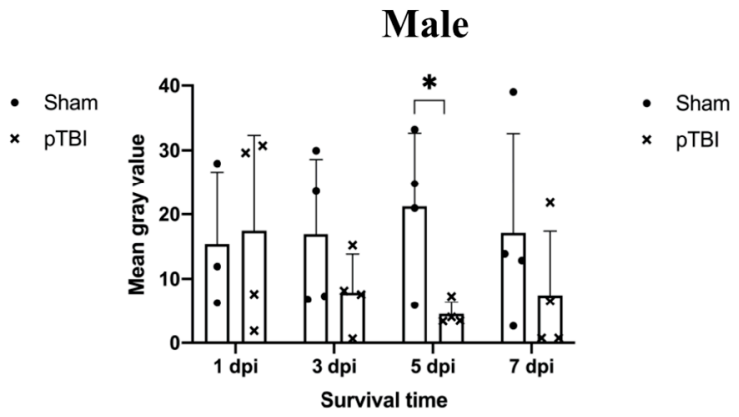

b

Figure 5. Comparison of CYP1B1 mRNA expression in hippocampal subregion CA2 in rats subjected to either sham-surgery or pTBI. Animals in Sham received a craniotomy, while animals in pTBI received a craniotomy with a subsequent pTBI. Survival times analyzed were 1-, 3-, 5- and 7 days. CYP1B1 mRNA was detected by in situ hybridization. Graphs show a timeline over CYP1B1 mRNA expression in subregion CA2 of females (a) and males (b) subjected to either sham-surgery or pTBI. The mean gray value is presented in the Y-axis, showing the average mean gray area calculated from each measured cell for each subregion and animal. To calculate mean gray value, images were made binary and in-situ probes made black and separated from the white background. The gray value of the color black was set to 255 and the value for white to 0 . The gray value of each cell is therefore a measurement of the area of cell marked by the in-situ probe. The gray values from each cell of each subregion were then used to calculate the mean gray value of each subregion and animal. The $\mathrm{X}$-axis shows the survival time. Males show no change in CYP1B1 mRNA expression $1 \mathrm{dpi}$, but $3-, 5-$, and 7 dpi expression is decreased in the groups receiving pTBI compared to those receiving sham-surgery (b). $5 \mathrm{dpi}$, males subjected to pTBI exhibited significantly lower expression compared to sham in CA2 $(p=0.0349)$. The values are presented as mean + SD for each group, including the mean for each animal. Horizontal bars marked with "**" show differences where $p<0.05$. Abbreviations: CA2: Cornu Ammonis 2, CYP1B1: Cytochrome P450 1B1, DG: Dentate gyrus, dpi: days post-injury, pTBI: penetrating traumatic brain injury.

\subsection{Immunohistochemistry}

Regardless of sex, intervention and survival time, qualitative analysis determined colocalization of CYP1B1 and NeuN in every hippocampal subregion. No apparent differences were noted between subregions or groups stated above (Figure 6). For CPR and NeuN, distinct colocalization was only observed in subregions CA1 and CA2. This was true regardless of sex, intervention, and survival time. Regarding colocalization in CA1 and CA2, no apparent differences were observed between the groups. 

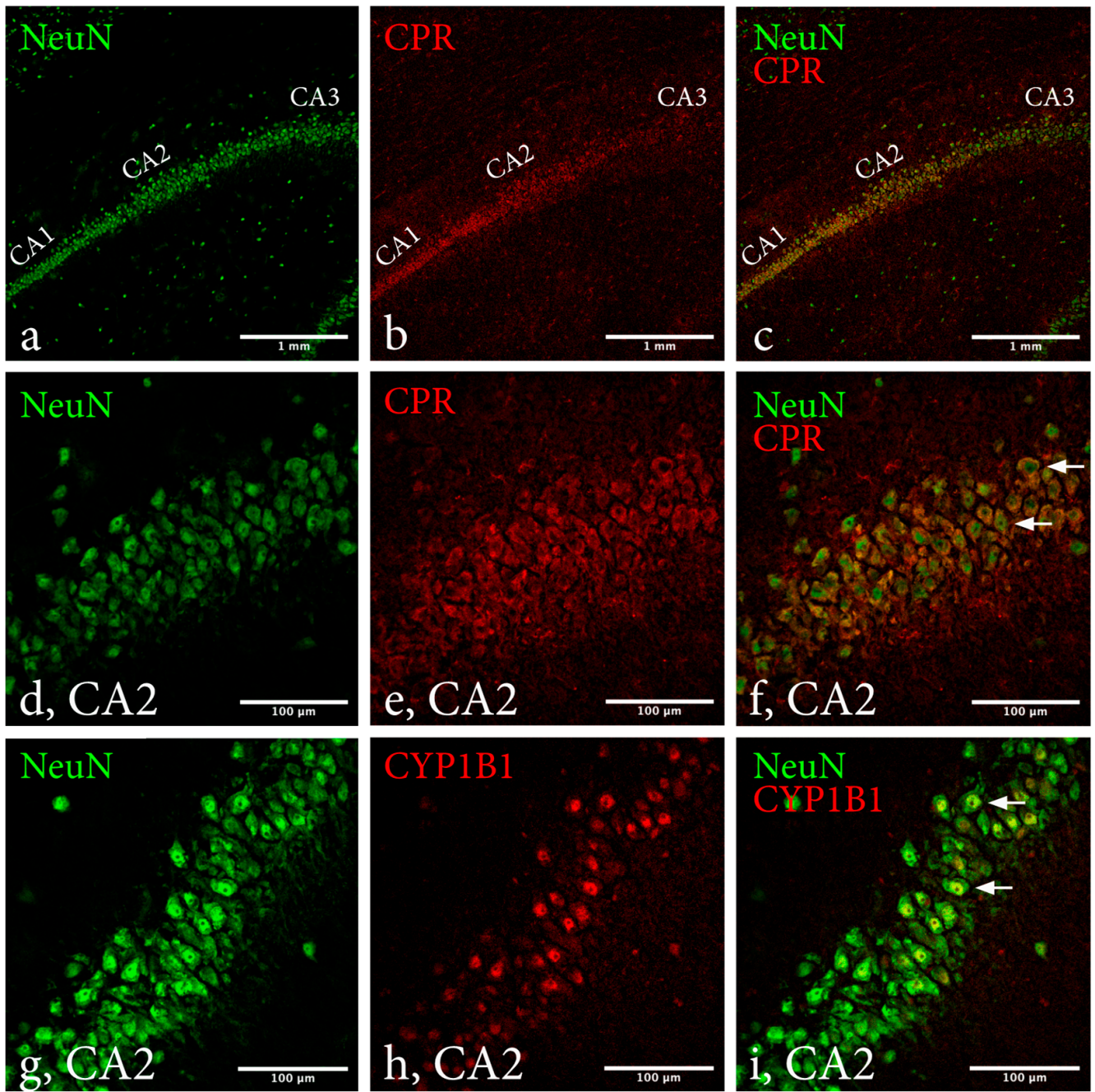

Figure 6. Immunohistochemical evaluation of CYP1B1 and CPR colocalization with NeuN in hippocampal subregions. Confocal images depicting an overview of CA1, CA2 and CA3 at $10 \times$ magnification $(\mathbf{a}-\mathbf{c})$, subregion CA2 captured at $40 \times$ magnification $(\mathbf{d}-\mathbf{i})$. Green channel $(\mathbf{a}, \mathbf{d}, \mathbf{g})$ depicts NeuN staining, red channel $(\mathbf{b}, \mathbf{e}, \mathbf{h})$ CPR or CYP1B1 and $(\mathbf{c}, \mathbf{f}, \mathbf{i})$ the two channels merged. Distinct colocalization of CPR and NeuN was observed in subregions CA1 and CA2, but not CA3 (c). Positive colocalization of CYP1B1 and NeuN was noted in several cells, indicating presence of CYP1B1 protein in CA2 neurons (i). Examples of cells judged as positive for CPR or CYP1B1 are marked by arrows. The image was deemed representative of all groups, as no apparent difference was observed between sexes, interventions, or survival times. Abbreviations: CA2: Cornu Ammonis 2, CPR: Cytochrome P450 reductase, CYP1B1: Cytochrome P450 1B1.

\subsection{Estrus Cycle Staging}

Estrus cycle staging was performed on all 31 females using standard hematoxylineosin staining. In females receiving sham-surgery, 7 were staged in phases of the estrus cycle characterized by low estradiol levels while 10 were staged as proestrus, a phase characterized by high E2 levels. In females subjected to pTBI, 5 were staged in phases characterized by low E2 levels while 9 were staged as proestrus, characterized by high E2 levels.

\section{Discussion}

CYP1B1 metabolizes the neuroprotective sex hormones $17 \beta$-estradiol (E2) and progesterone and modulates the inflammatory response by producing HETEs [12,30,31]. CYP1B1 activity directly correlates to its electron donor Cytochrome P450 reductase (CPR). 
Female rodents exhibit superior outcome following TBI and multiple sequala are linked to hippocampal dysfunction [32-34].

Therefore, this study aimed to describe hippocampal CYP1B1 mRNA expression as well as protein presence of CYP1B1 and CPR in rats subjected to PTBI and determine if there were indications of sex-dependent differences.

The study is underpowered due to the lack of previous information regarding CYP1B1 mRNA expression in relation to the hippocampal subregions and TBI. Subregional CYP1B1 mRNA expression has not been previously studied and we could therefore not perform a reliable power analysis, and instead performed an experimental pilot study aiming at identifying key timepoints for future studies. Post-hoc analysis based on the results presented in this article show close to a total 200 animals would be necessary assuming the same number of groups, alpha $=0.5$ and $80 \%$ power. We therefore intend to perform future studies with increased power, aimed at targeted timepoints to limit the number of animals used.

In this study, our results show homogenous presence of CYP1B1 protein while CPR is predominantly concentrated to subregions CA1 and CA2. Furthermore, we show CYP1B1 mRNA expression in every hippocampal subregion before and after pTBI, with distinct interregional differences and possible sex-dependent differences in expression.

CYP1B1 mRNA expression in every hippocampal subregion irrespective of intervention was expected, as E2 and progesterone are vital for brain function [35,36]. For every group, expression was greatest in CA2 and lowest in DG. These findings were confirmed using ViewRNA as an alternate method for mRNA in situ-hybridization. Interestingly, the distinct presence of CPR in subregions CA1 and CA2 are in line with our findings of CYP1B1 mRNA possessing interregional differences in expression with a concentration to CA2. As a key redox partner to CYP1B1 necessary for its activity, the concentration of CPR to subregion CA2 further implies importance of CYP1B1 in CA2 compared to other subregions.

Males subjected to sham-surgery exhibited a higher expression in CA2 at every timepoint when compared to females, possibly explained by sex-dependent differences in hippocampal E2 concentrations. In contrast to peripheral E2, hippocampal E2 concentrations are higher in males than in females [37]. Additionally, previous research has shown CA2 exhibits differences in genetic expression profile compared to other subregions [26], most notably genes linked to growth factor signaling and signal transduction.

Our results indicate that changes in CA2 CYP1B1 expression in pTBI are sex dependent. Expression 1 dpi was unaffected in males whilst reduced in females. Male peak expression occurred $1 \mathrm{dpi}$, followed by reduced expression 3,5 and $7 \mathrm{dpi}$. Females reached peak expression $3 \mathrm{dpi}$ and no difference in expression was noted $7 \mathrm{dpi}$. Previous studies have described sex-dependent divergence in acute neuroinflammatory response to TBI, males having a more acute inflammatory response than females [38,39]. CYP1B1 mRNA is induced by cytokines like TNF-alpha and aryl hydrocarbon receptor ligands [40], this inflammatory divergence could contribute to differences observed in CYP1B1 expression. However, our results suggest that the overall effect of pTBI on CYP1B1 is reduced expression, indicating that other regulatory factors counterbalance induction driven by neuroinflammation.

Males subjected to sham-surgery exhibited higher CYP1B1 mRNA expression in CA2 at every timepoint compared to females. However, after pTBI female expression was higher $3 \mathrm{dpi}$ and equal to male expression $5 \mathrm{dpi}$. Extracerebral CYP1B1 is regulated by both hormonal factors and through the aryl hydrocarbon receptor [41]. Both estrogens and progesterone can induce CYP1B1 mRNA expression and protein synthesis in fibroblasts [42]. If applicable to hippocampal neurons, increase of female CYP1B1 mRNA expression in CA2 may be due to increased BBB-leakage occurring following TBI [43], allowing estrogen and progesterone to enter the CNS. CYP1B1 is involved in BBB-permeability, and the altered expression following injury may influence BBB integrity [44]. Our model causes increased BBB-leakage, peaking $3 \mathrm{dpi}$ and thereafter declining [28]. As peripheral E2 and progesterone concentrations are higher in females than males, it could possibly affect females more 
than males. In this study, females lacked synchronized estrus cycle, resulting in too small populations to draw statistical conclusions regarding correlation of CYP1B1 mRNA expression and estrus cycle phase.

The penetration model used lacerates the fornix, depriving the hippocampus of input, resulting in impaired spatial memory function [45]. The laceration occurs rostrally of the fimbria projecting to the hippocampal subregions, affecting afferent input and retrograde atrophy in all subregions to equal extent. Nonetheless, effects of this altered input may differ regarding CYP1B1 expression, as CA2 possesses an innate resistance to ischemia and TBI relative to other subregions [26].

The effect of altered CYP1B1 expression is beyond the scope of this study. There is however evidence of both positive and negative effects of altered CYP1B1 protein levels indicating that CYP1B1 acts on both beneficial and deleterious pathways. A previous study [5] showed that CYP1B1 deficiency resulted in increased oxidative stress and reduced angiogenesis. On the contrary, there are evidence of 20-HETE-antagonists reducing lesion area in ischemic injuries [14]. Furthermore, CYP1B1 metabolizes E2, which besides its neuroprotective properties [40-43] is essential for hippocampal functions frequently effected by TBI [35]. CYP1B1 also metabolizes progesterone [4], which possesses similar neuroprotective and anti-inflammatory properties as E2 but is also involved in the pathophysiology of posttraumatic epilepsy [46]. Treatment of posttraumatic epilepsy may be altered depending on CYP1B1 protein levels as susceptibility to anti-epileptic drugs alters with CYP1B1 single-nucleotide polymorphism [13]. Moreover, CYP1B1 catalyzes both steps in the production of retinoic acid from retinol [4]. Retinoic acid possesses several neuroprotective traits after TBI [47] and contributes to hippocampal neurogenesis [48]. In this study we suggest CYP1B1 mRNA is expressed in all hippocampal subregions with distinct interregional differences. However, future studies with increased power will be required to confirm our preliminary findings, and thereafter if altered CYP1B1 expression influences inflammatory and neuroprotective molecules in pTBI.

\section{Materials and Methods}

The study was approved by the Swedish regional ethics approval board for animal research (N244/15).

\subsection{Material}

A total 32 male and 32 female adult Sprague Dawley rats received sham-surgery or pTBI and were designated a survival time of 24-, 72-, 120- or $168 \mathrm{~h}$. Each group contained four male and four female rats (Table 1). One male rat exposed to sham-surgery and a survival time of 24-h was excluded due to brain malformation and one female rat subjected to pTBI and a survival time of 168 -h was excluded due to contralateral cortical injuries observed during organ harvesting. Males weighed between 408 and $512 \mathrm{~g}$ (mean $=451.21 \mathrm{~g}$; $\mathrm{SD}=22.11 \mathrm{~g}$ ) and females weighed between 276 and $365 \mathrm{~g}$ (mean = 323.09 $\mathrm{g}$; $\mathrm{SD}=17.56 \mathrm{~g})$. Rats were kept in standard sized cages divided by sex in groups of two. A twelve-hour light/dark cycle was employed, and animals had free access to water and pellets.

\subsection{Statistics}

As the nature of the study is explorative and a pilot for future studies, group sizes were small and underpowered to reduce the number of animals used.

Statistical analysis was performed using GraphPad Prism 9 (GraphPad Software, San Diego, CA, USA). A two-way ANOVA followed by a Tukey multiple comparisons test was performed to analyze the effect of sex and intervention on CYP1B1 mRNA expression. Alpha level was set to 0.05 and $p$-values $<0.05$ were considered significant.

Post-hoc power analysis showed the study was underpowered and means were calculated for sham-surgery compared to pTBI (mean $=0.296, \mathrm{SD}=0.19)$, sex-differences following sham-surgery $($ mean $=0.16, \mathrm{SD}=0.13)$ and $\mathrm{pTBI}($ mean $=0.26, \mathrm{SD}=0.19)$. 
Table 1. Material composition based on sex, survival time and intervention.

\begin{tabular}{cccc}
\hline Intervention & Survival Time & Number of ISH & Number of IHC \\
\hline Sham-surgery & $24 \mathrm{~h}$ & Male $=3$, Female $=4$ & Male $=3$, Female $=4$ \\
\hline pTBI & $24 \mathrm{~h}$ & Male $=4$, Female $=4$ & Male $=4$, Female $=4$ \\
\hline Sham-surgery & $72 \mathrm{~h}$ & Male $=4$, Female $=4$ & Male $=4$, Female $=4$ \\
\hline pTBI & $72 \mathrm{~h}$ & Male $=4$, Female $=4$ & Male $=4$, Female $=4$ \\
\hline Sham-surgery & $120 \mathrm{~h}$ & Male $=4$, Female $=4$ & Male $=4$, Female $=4$ \\
\hline pTBI & $120 \mathrm{~h}$ & Male $=4$, Female $=4$ & Male $=4$, Female $=4$ \\
\hline Sham-surgery & $168 \mathrm{~h}$ & Male $=4$, Female $=4$ & Male $=4$, Female $=4$ \\
\hline pTBI & $168 \mathrm{~h}$ & Male $=4$, Female $=3$ & Male $=4$, Female $=3$ \\
\hline
\end{tabular}

Abbreviations: ISH: In situ hybridization, IHC: Immunohistochemistry, pTBI: Penetrating traumatic brain injury.

\subsection{Surgery and Penetrating Trauma}

Animals were anaesthetized in a sealed chamber containing $4 \%$ isoflurane. Thereafter, animals were equipped with a nose mask continuously supplying $2.0 \mathrm{~mL} / \mathrm{h}$ isoflurane and placed on a heated surgical platform. After midline incision through the skin and periosteum, a drill was used to create a $2.75 \mathrm{~mm}$ bore hole $2 \mathrm{~mm}$ posterior and $2 \mathrm{~mm}$ lateral of bregma, exposing the dura. Animals were then placed in a stereotactic frame with a secondary projectile adjacent to the dura. The secondary projectile consisted of a $30 \mathrm{~mm}$ long probe constructed in one single unit in aluminum. The penetrating pins diameter was $2 \mathrm{~mm}$ and its tip spherical. The probe weighed $0.66 \mathrm{~g}$ [27]. A modified air-rifle (CNC-Process AB, Hova, Sweden) was used to fire a lead pellet that impacted the secondary projectile which accelerated to a speed of $110 \mathrm{~m} / \mathrm{s}$ as it lacerated meninges and brain parenchyma. A cone shaped section of the secondary probe limited mean penetration depth to $5.12 \mathrm{~mm}(\mathrm{n}=32 ; \mathrm{SD}=0.06 \mathrm{~mm})$. For animals subjected to sham-surgery, a blank bullet was used and thus no penetration occurred. Lastly, the skin was sutured, and the animals were returned to their cages. A schematic illustration of the model is presented in Figure 7. Previous studies describing the penetration model in further depth are available $[27,28]$.

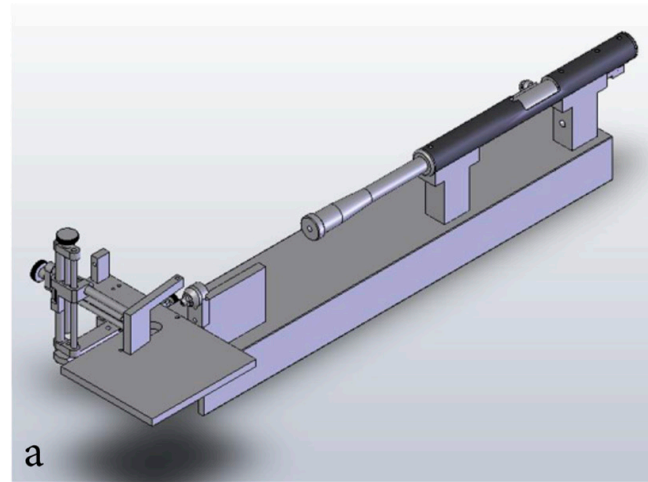

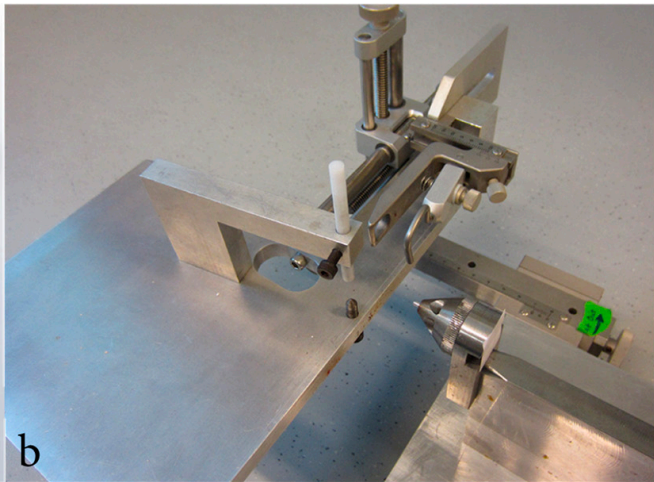

Spherical aluminium

Radius $1 \mathrm{~mm}$

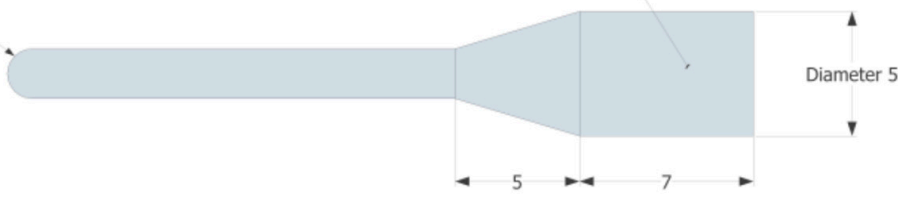

C

Figure 7. Schematic illustration of the equipment used for inducing penetrating traumatic brain injury. Schematic illustration of the trauma model (a), image of the stereotactic frame, animal platform and cone formed probe guider (b). Schematic illustration of secondary impactor probe design (c). 


\subsection{Tissue Sectioning}

After sacrifice, brains were removed and fresh frozen on dry ice until placed in a $-70{ }^{\circ} \mathrm{C}$ freezer. Brains were cut into $14 \mu \mathrm{m}$ coronal sections using a Thermo Fisher NX70 cryostat and mounted onto Thermo Fisher Superfrost plus glass and stored in $-70{ }^{\circ} \mathrm{C}$. Sections used were located between Bregma: $-3.84 \mathrm{~mm}$ and Bregma: $-4.80 \mathrm{~mm}$.

Removal of female reproductive organs was performed in conjunction with animal sacrifice and the tissue was placed in formaldehyde and thereafter a $5^{\circ} \mathrm{C}$ refrigerator overnight. $14 \mu \mathrm{m}$ sections were then cut in a Thermo Fisher NX70 cryostat and mounted onto Thermo Fisher Superfrost plus glass.

\subsection{In-Situ Hybridization}

mRNA in-situ hybridization was performed using both RNAscope (ACD, Santa Ana, CA, USA) and ViewRNA (ThermoFisher Scientific, Carlsbad, CA, USA), for both methods the companies recommended probe aimed at targeting CYP1B1 mRNA was used.

The RNAscope technique utilizes paired oligonucleotide target probes with a double-Z design and subsequent signal amplification to visualize single mRNA molecules [49]. Insitu hybridization was performed according to the manufacturer's instructions with the sole exception being a reduced proteas time from $30 \mathrm{~min}$ to $25 \mathrm{~min}$. Target probe used was RnCYP1B1 (ACD, Catalog No: 493211) and reagent RNAscope ${ }^{\circledR} 2.5$ HD Detection ReagentsBROWN (ACD, Catalog No: 322310). After Cresyl violet counterstaining mounting was performed with Entellan.

ViewRNA is an alternative method for mRNA in-situ hybridization and was used as a positive control to RNAscope. In contrast to RNAscope, ViewRNA utilizes oligonucleotides combined with branched DNA for signal detection and amplification [50]. ViewRNA Tissue Assay Core Kit (ThermoFisher Scientific, Catalog No: 19931) and target probe Rat CYP1B1 (ThermoFisher Scientific, Catalog No: VPU62U6) were used according to the manufacturer's instructions and counterstained using methyl green.

\subsection{Estrus Cycle Determination}

Tissue from the ovaries, uterus and vagina were stained with hematoxylin-eosin according to standard protocol. The estrous cycle stage was determined by applying the criteria described by Westwood [51].

\subsection{Immunohistochemistry}

Immunohistochemistry was performed on $14 \mu \mathrm{m}$ coronal brain sections. Slides were placed in room temperature for $30 \mathrm{~min}$, and thereafter placed in $4 \%$ buffered formaldehyde for $10 \mathrm{~min}$. Slides were then rinsed in $0.01 \mathrm{M}$ PBS and incubated in a humid chamber at $5{ }^{\circ} \mathrm{C}$ for $21 \mathrm{~h}$ with either CYP1B1 antibody (Abcam, Product ID: ab185954) diluted 1:2000 or CPR antibody (Abcam, Product ID: ab180597) diluted 1:100 together with NeuN antibody (Millipore, Catalog No: MAB377) diluted 1:1000, 5\% donkey serum and $95 \%$ primary buffer $(0.01 \mathrm{M}$ PBS $+0.1 \% \mathrm{NaN} 3+0.3 \%$ triton $+5 \%$ bovine serum albumin). Thereafter, slides were rinsed in $0.01 \mathrm{M}$ PBS and incubated in room temperature for 30 min with secondary antibodies Cy3 (Jackson ImmunoResearch, Product ID: 711165152) and Alexa Flour 488 (Jackson ImmunoResearch, Product ID: 715545150), both diluted 1:400 with secondary buffer $(0.01 \mathrm{M}$ PBS $+0.1 \% \mathrm{NaN} 3+0.3 \%$ triton). Thereafter slides were rinsed in $0.01 \mathrm{M}$ PBS and mounted with Mowiol.

\subsection{Image Analysis}

Images used to analyze the in-situ hybridization were acquired at $20 \times$ magnification using a brightfield Nikon Eclipse Ni-E microscope equipped with a Nikon-Fi2 camera. Imaging locations were pre-decided and are described in Figure 8. Images were analyzed in ImageJ/Fiji. Each granule and pyramidal cell were marked with a region of interest (ROI) corresponding to the average cell size of the subregion (CA1 $=1880$ pixels; $C A 2=2162$ pixels; $\mathrm{CA} 3=2644$ pixels; $\mathrm{CA} 4=2372$ pixels and $\mathrm{DG}=1456$ pixels). Images were then made 
binary, and a manual threshold was applied by a blinded assessor. Thereafter, the mean gray value for each marked ROI was used to calculate the subregions average mean gray value. Data was transferred to GraphPad Prism 8.

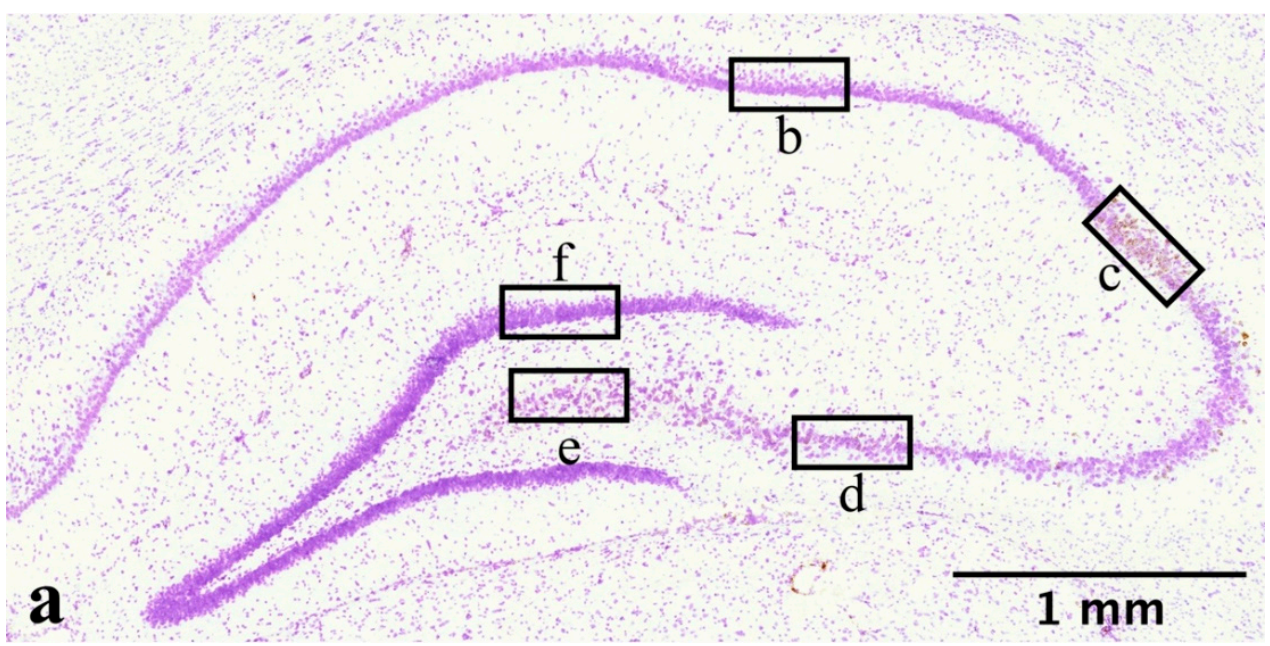

Figure 8. Overview of hippocampal anatomy and locations of image acquisition. Stitched image (a) of ipsilateral hippocampus of female rat subjected to penetrating traumatic brain injury and a survival time of 3 days. Acquired at $20 \times$ magnification using a Nikon Eclipse Ni-E microscope. Acquired at Bregma: $-3.84 \mathrm{~mm}$. RNAscope in-situ hybridization marked CYP1B1 mRNA in brown. Black boxes (b-f) show location and scope of image captured as well as CYP1B1 mRNA markings. Box (b) depicts CA1, (c) CA2, (d) CA3, (e) CA4 and (f) DG. Abbreviations: CA: Cornu Ammonis, CYP1B1: Cytochrome P450 1B1, DG: Dentate Gyrus.

To assess CYP1B1 and CPR colocalization with NeuN, a Nikon Eclipse E600 equipped with a Nikon C1 confocal system with an Argon Ion Laser $488 \mathrm{~nm}$ (40 mW) and a HeNe Laser $543 \mathrm{~nm}(1.0 \mathrm{~mW})$ was used to acquire images at $40 \times$ magnification. Qualitative analysis of the images was performed by a blinded assessor.

\section{Conclusions}

CYP1B1 mRNA is expressed in every hippocampal subregion with indications of sex-dependent and interregional differences. Furthermore, we show these differences may persist after pTBI. CYP1B1 expression was greatest in CA2 regardless of sex and intervention. We also suggest that the temporal pattern of expression following pTBI exhibits indications of sex-dependent differences regarding time of response, peak expression, and normalization. Immunohistochemical analysis showed CYP1B1 protein in neurons of all hippocampal subregions irrespective of sex, while CPR colocalization was concentrated to CA1 and CA2. If our results are confirmed by future studies and altered CYP1B1 mRNA expression correlates to levels of CYP1B1 protein, male and female rodents may have a different inherent neuroprotective and inflammatory response to pTBI. Furthermore, the concentration of CYP1B1 mRNA and CPR protein to CA2 may indicate an unknown importance of CYP1B1 activity for CA2 function.

Author Contributions: M.K.S. and M.R. planned the study. Animal experiments were performed by J.D. and E.L. Laboratory experiments were performed by M.A. and E.L. Analysis was performed by E.L., M.K.S. and M.R. All authors have read and agreed to the published version of the manuscript.

Funding: This research was funded by the Swedish Armed Forces (AF.9221006).

Institutional Review Board Statement: The study was approved by the Swedish regional ethics approval board for animal research (N244/15).

Data Availability Statement: Data is available through Mendeley Data, at doi:10.17632/dpp455r2jv.1. 
Conflicts of Interest: The authors declare no conflict of interest. The funders had no role in the design of the study; in the collection, analyses, or interpretation of data; in the writing of the manuscript, or in the decision to publish the results.

$\begin{array}{ll}\text { Abbreviations } \\ \text { AA } & \text { arachidonic acid } \\ \text { BBB } & \text { blood-brain-barrier } \\ \text { CA } & \text { Cornu Ammonis } \\ \text { CPR } & \text { Cytochrome P450 reductase } \\ \text { CYP } & \text { Cytochrome P450 } \\ \text { CYP1B1 } & \text { Cytochrome P450 1B1 } \\ \text { DG } & \text { Dentate Gyrus } \\ \text { dpi } & \text { days post-injury } \\ \text { E2 } & \text { 17ß-estradiol } \\ \text { HETEs } & \text { hydroxyeicosatetraenoic acids } \\ \text { IHC } & \text { immunohistochemistry } \\ \text { ISH } & \text { in situ hybridization } \\ \text { pTBI } & \text { penetrating traumatic brain injury } \\ \text { ROI } & \text { region of interest } \\ \text { TBI } & \text { traumatic brain injury }\end{array}$

\section{Appendix A}

Table A1. Data extracted from gen array of whole hippocampi and cortical tissue from rats subjected to sham-surgery or pTBI [3].

\begin{tabular}{cccccccc}
\hline & CYP1A1 & CYP1A2 & CYP1B1 & CYP2A1 & CYP2A2 & CYP2E1 & CPR \\
\hline $\begin{array}{c}\text { Hippocampus } \\
\text { pTBI vs. Sham } \\
\text { Fold change }\end{array}$ & 1.30 & 1.16 & 15.03 & 1.11 & 1.10 & 1.17 & 1.99 \\
\hline $\begin{array}{c}\text { Cortex pTBI vs. } \\
\text { Sham Fold change }\end{array}$ & 1.08 & 1.04 & 4.65 & 1.08 & -1.18 & 1.08 & -1.63 \\
\hline
\end{tabular}

Abbreviations: CYP1A1: Cytochrome P450 1A1, CYP1A2: Cytochrome P450 1A2, CYP1B1: Cytochrome P450 1B1, CYP2A1: Cytochrome P450 2A1, CYP2A2: Cytochrome P450 2E1, CPR: Cytochrome P450 reductase, pTBI: Penetrating traumatic brain injury.

\section{References}

1. Sheriff, F.G.; Hinson, H.E. Pathophysiology and Clinical Management of Moderate and Severe Traumatic Brain Injury in the ICU. Semin. Neurol. 2015, 35, 42-49. [CrossRef]

2. Stein, D.G. Embracing failure: What the Phase III progesterone studies can teach about TBI clinical trials. Brain Inj. 2015, 29, 1259-1272. [CrossRef]

3. Risling, M.; Plantman, S.; Angeria, M.; Rostami, E.; Bellander, B.-M.; Kirkegaard, M.; Arborelius, U.; Davidsson, J. Mechanisms of blast induced brain injuries, experimental studies in rats. NeuroImage 2011, 54 (Suppl. 1), S89-S97. [CrossRef] [PubMed]

4. Li, F.; Zhu, W.; Gonzalez, F.J. Potential role of CYP1B1 in the development and treatment of metabolic diseases. Pharmacol. Ther. 2017, 178, 18-30. [CrossRef]

5. $\quad$ Palenski, T.L.; Gurel, Z.; Sorenson, C.M.; Hankenson, K.D.; Sheibani, N. Cyp1B1 expression promotes angiogenesis by suppressing NF-кB activity. Am. J. Physiol.-Cell Physiol. 2013, 305, C1170-C1184. [CrossRef] [PubMed]

6. Maayah, Z.H.; Althurwi, H.N.; El-Sherbeni, A.A.; Abdelhamid, G.; Siraki, A.G.; El-Kadi, A.O. The role of cytochrome P450 $1 \mathrm{~B} 1$ and its associated mid-chain hydroxyeicosatetraenoic acid metabolites in the development of cardiac hypertrophy induced by isoproterenol. Mol. Cell. Biochem. 2017, 429, 151-165. [CrossRef] [PubMed]

7. Farias, S.E.; Basselin, M.; Chang, L.; Heidenreich, K.A.; Rapoport, S.I.; Murphy, R.C. Formation of eicosanoids, E2/D2 isoprostanes, and docosanoids following decapitation-induced ischemia, measured in high-energy-microwaved rat brain. J. Lipid Res. 2008, 49, 1990-2000. [CrossRef]

8. Tsuchiya, Y.; Nakajima, M.; Yokoi, T. Cytochrome P450-mediated metabolism of estrogens and its regulation in human. Cancer Lett. 2005, 227, 115-124. [CrossRef]

9. Day, N.L.; Floyd, C.L.; D'Alessandro, T.L.; Hubbard, W.J.; Chaudry, I.H. 17 $\beta$-Estradiol Confers Protection after Traumatic Brain Injury in the Rat and Involves Activation of G Protein-Coupled Estrogen Receptor. J. Neurotrauma 2013, 30, 1531-1541. [CrossRef] 
10. Lu, H.; Ma, K.; Jin, L.; Zhu, H.; Cao, R. 17ß-estradiol rescues damages following traumatic brain injury from molecule to behavior in mice. J. Cell. Physiol. 2018, 233, 1712-1722. [CrossRef]

11. Wang, J.; Hou, Y.; Zhang, L.; Liu, M.; Zhao, J.; Zhang, Z.; Ma, Y.; Hou, W. Estrogen Attenuates Traumatic Brain Injury by Inhibiting the Activation of Microglia and Astrocyte-Mediated Neuroinflammatory Responses. Mol. Neurobiol. 2021, 58, $1052-1061$. [CrossRef]

12. Guennoun, R. Progesterone in the Brain: Hormone, Neurosteroid and Neuroprotectant. Int. J. Mol. Sci. 2020, 21, 5271. [CrossRef] [PubMed]

13. Silva-Alves, M.S.; Secolin, R.; Carvalho, B.S.; Yasuda, C.L.; Bilevicius, E.; Alvim, M.K.M.; Santos, R.O.; Maurer-Morelli, C.V.; Cendes, F.; Lopes-Cendes, I. A Prediction Algorithm for Drug Response in Patients with Mesial Temporal Lobe Epilepsy Based on Clinical and Genetic Information. PLoS ONE 2017, 12, e0169214. [CrossRef] [PubMed]

14. Renic, M.; Klaus, J.A.; Omura, T.; Kawashima, N.; Onishi, M.; Miyata, N.; Koehler, R.C.; Harder, D.R.; Roman, R.J. Effect of 20-HETE Inhibition on Infarct Volume and Cerebral Blood Flow after Transient Middle Cerebral Artery Occlusion. J. Cereb. Blood Flow Metab. 2009, 29, 629-639. [CrossRef] [PubMed]

15. Gu, J.; Weng, Y.; Zhang, Q.Y.; Cui, H.; Behr, M.; Wu, L.; Yang, W.; Zhang, L.; Ding, X. Liver-specific deletion of the NADPHcytochrome P450 reductase gene: Impact on plasma cholesterol homeostasis and the function and regulation of microsomal cytochrome P450 and heme oxygenase. J. Biol. Chem. 2003, 278, 25895-25901. [CrossRef]

16. Henderson, C.J.; Pass, G.J.; Wolf, C.R. The hepatic cytochrome P450 reductase null mouse as a tool to identify a successful candidate entity. Toxicol. Lett. 2006, 162, 111-117. [CrossRef] [PubMed]

17. Günther, M.; Plantman, S.; Davidsson, J.; Angéria, M.; Mathiesen, T.; Risling, M. COX-2 regulation and TUNEL-positive cell death differ between genders in the secondary inflammatory response following experimental penetrating focal brain injury in rats. Acta Neurochir. 2015, 157, 649-659. [CrossRef] [PubMed]

18. Roof, R.L.; Duvdevani, R.; Stein, D.G. Gender influences outcome of brain injury: Progesterone plays a protective role. Brain Res. 1993, 607, 333-336. [CrossRef]

19. Jones, N.C.; Constantin, D.; Prior, M.J.W.; Morris, P.G.; Marsden, C.A.; Murphy, S. The neuroprotective effect of progesterone after traumatic brain injury in male mice is independent of both the inflammatory response and growth factor expression. Eur. $J$. Neurosci. 2005, 21, 1547-1554. [CrossRef]

20. Ottochian, M.; Salim, A.; Berry, C.; Chan, L.S.; Wilson, M.T.; Margulies, D.R. Severe traumatic brain injury: Is there a gender difference in mortality? Am. J. Surg. 2009, 197, 155-158. [CrossRef] [PubMed]

21. Czosnyka, M.; Radolovich, D.; Balestreri, M.; Lavinio, A.; Hutchinson, P.; Timofeev, I.; Smielewski, P.; Pickard, J.D. Gender-related differences in intracranial hypertension and outcome after traumatic brain injury. In Acta Neurochirurgica Supplements; Springer: Vienna, Austria, 2008; Volume 102, pp. 25-28. [CrossRef]

22. Davis, D.P.; Douglas, D.J.; Smith, W.; Sise, M.J.; Vilke, G.M.; Holbrook, T.L.; Kennedy, F.; Eastman, A.B.; Velky, T.; Hoyt, D.B Traumatic Brain Injury Outcomes in Pre- and Post- Menopausal Females Versus Age-Matched Males. J. Neurotrauma 2006, 23, 140-148. [CrossRef] [PubMed]

23. Berry, C.; Ley, E.J.; Tillou, A.; Cryer, G.; Margulies, D.R.; Salim, A. The Effect of Gender on Patients with Moderate to Severe Head Injuries. J. Trauma 2009, 67, 950-953. [CrossRef] [PubMed]

24. Schultz, C.; Engelhardt, M. Anatomy of the Hippocampal Formation. Front. Neurol. Neurosci. 2014, 34, 6-17. [CrossRef] [PubMed]

25. Cembrowski, M.S.; Spruston, N. Heterogeneity within classical cell types is the rule: Lessons from hippocampal pyramidal neurons. Nat. Rev. Neurosci. 2019, 20, 193-204. [CrossRef] [PubMed]

26. Dudek, S.M.; Alexander, G.; Farris, S. Rediscovering area CA2: Unique properties and functions. Nat. Rev. Neurosci. 2016, 17, 89-102. [CrossRef]

27. Davidsson, J.; Risling, M. Characterization of pressure distribution in penetrating traumatic brain injuries. Front. Neurol. 2015, 6, 51. [CrossRef]

28. Plantman, S.; Ng, K.C.; Lu, J.; Davidsson, J.; Risling, M. Characterization of a Novel Rat Model of Penetrating Traumatic Brain Injury. J. Neurotrauma 2012, 29, 1219-1232. [CrossRef]

29. Davidsson, J.; Risling, M. Experimental Models for Neurotrauma Research. In Injury Models of the Central Nervous System: Methods and Protocols; Kobeissy, F.H., Dixon, C.E., Hayes, R.L., Mondello, S., Eds.; Springer: New York, NY, USA, 2016; pp. $267-288$.

30. Yu, X.; Wu, J.; Hu, M.; Wu, J.; Zhu, Q.; Yang, Z.; Xie, X.; Feng, Y.-Q.; Yue, J. Glutamate affects the CYP1B1- and CYP2U1-mediated hydroxylation of arachidonic acid metabolism via astrocytic mGlu5 receptor. Int. J. Biochem. Cell Biol. 2019, 110, 111-121. [CrossRef]

31. Arevalo, M.-A.; Azcoitia, I.; Garcia-Segura, L.M. The neuroprotective actions of oestradiol and oestrogen receptors. Nat. Rev. Neurosci. 2015, 16, 17-29. [CrossRef]

32. Paterno, R.; Folweiler, K.A.; Cohen, A.S. Pathophysiology and Treatment of Memory Dysfunction After Traumatic Brain Injury. Curr. Neurol. Neurosci. Rep. 2017, 17, 52. [CrossRef]

33. Schmitt, S.; Dichter, M.A. Electrophysiologic recordings in traumatic brain injury. Handb. Clin. Neurol. 2015, 127, 319-339.

34. Wolf, J.A.; Koch, P.F. Disruption of Network Synchrony and Cognitive Dysfunction After Traumatic Brain Injury. Front. Syst. Neurosci. 2016, 10, 43. [CrossRef] [PubMed]

35. Taxier, L.R.; Gross, K.S.; Frick, K.M. Oestradiol as a neuromodulator of learning and memory. Nat. Rev. Neurosci. 2020, 21, 535-550. [CrossRef] [PubMed] 
36. Mannella, P.; Simoncini, T.; Genazzani, A.R. Estrogens and progestins: Molecular effects on brain cells. Horm. Mol. Biol. Clin. Investig. 2010, 4, 609-613. [CrossRef]

37. Kato, A.; Hojo, Y.; Higo, S.; Komatsuzaki, Y.; Murakami, G.; Yoshino, H.; Uebayashi, M.; Kawato, S. Female hippocampal estrogens have a significant correlation with cyclic fluctuation of hippocampal spines. Front. Neural Circuits 2013, 7, 149. [CrossRef]

38. Doran, S.J.; Ritzel, R.M.; Glaser, E.P.; Henry, R.; Faden, A.I.; Loane, D. Sex Differences in Acute Neuroinflammation after Experimental Traumatic Brain Injury Are Mediated by Infiltrating Myeloid Cells. J. Neurotrauma 2018, 36, 1040-1053. [CrossRef] [PubMed]

39. Villapol, S.; Loane, D.J.; Burns, M.P. Sexual dimorphism in the inflammatory response to traumatic brain injury. Glia 2017, 65 , 1423-1438. [CrossRef]

40. Drozdzik, A.; Dziedziejko, V.; Kurzawski, M. IL-1 and TNF- $\alpha$ regulation of aryl hydrocarbon receptor (AhR) expression in HSY human salivary cells. Arch. Oral Biol. 2014, 59, 434-439. [CrossRef]

41. Bhattacharyya, K.K.; Brake, P.B.; Eltom, S.E.; Otto, S.A.; Jefcoate, C.R. Identification of a rat adrenal cytochrome P450 active in polycyclic hydrocarbon metabolism as rat CYP1B1. Demonstration of a unique tissue-specific pattern of hormonal and aryl hydrocarbon receptor-linked regulation. J. Biol. Chem. 1995, 270, 11595-11602. [CrossRef]

42. Christou, M.; Savas, U.; Schroeder, S.; Shen, X.; Thompson, T.; Gould, M.N.; Jefcoate, C.R. Cytochromes CYP1A1 and CYP1B1 in the rat mammary gland: Cell-specific expression and regulation by polycyclic aromatic hydrocarbons and hormones. Mol. Cell. Endocrinol. 1995, 115, 41-50. [CrossRef]

43. Dell'Aquila, M.; Maiese, A.; De Matteis, A.; Viola, R.V.; Arcangeli, M.; La Russa, R.; Fineschi, V. Traumatic brain injury: Estimate of the age of the injury based on neuroinflammation, endothelial activation markers and adhesion molecules. Histol. Histopathol. 2021, 36, 795-806.

44. Ziegler, N.; Awwad, K.; Fisslthaler, B.; Reis, M.; Devraj, K.; Corada, M.; Minardi, S.P.; Dejana, E.; Plate, K.H.; Fleming, I.; et al. $\beta$-Catenin Is Required for Endothelial Cyp1b1 Regulation Influencing Metabolic Barrier Function. J. Neurosci. 2016, 36, 8921-8935. [CrossRef]

45. Roland, J.J.; Stewart, A.L.; Janke, K.L.; Gielow, M.R.; Kostek, J.A.; Savage, L.M.; Servatius, R.; Pang, K.C. Medial Septum-Diagonal Band of Broca (MSDB) GABAergic Regulation of Hippocampal Acetylcholine Efflux Is Dependent on Cognitive Demands. J. Neurosci. 2014, 34, 506-514. [CrossRef]

46. Ghadiri, T.; Vakilzadeh, G.; Hajali, V.; Khodagholi, F. Progesterone modulates post-traumatic epileptogenesis through regulation of BDNF-TrkB signaling and cell survival-related pathways in the rat hippocampus. Neurosci. Lett. 2019, 709, 134384. [CrossRef]

47. Hummel, R.; Ulbrich, S.; Appel, D.; Li, S.; Hirnet, T.; Zander, S.; Bobkiewicz, W.; Gölz, C.; Schäfer, M.K. Administration of all-trans retinoic acid after experimental traumatic brain injury is brain protective. Br. J. Pharmacol. 2020, 177, 5208-5223. [CrossRef] [PubMed]

48. Mishra, S.; Kelly, K.K.; Rumian, N.L.; Siegenthaler, J.A. Retinoic Acid Is Required for Neural Stem and Progenitor Cell Proliferation in the Adult Hippocampus. Stem Cell Rep. 2018, 10, 1705-1720. [CrossRef] [PubMed]

49. Wang, F.; Flanagan, J.; Su, N.; Wang, L.C.; Bui, S.; Nielson, A.; Wu, X.; Vo, H.-T.; Ma, X.-J.; Luo, Y.; et al. RNAscope: A novel in situ RNA analysis platform for formalin-fixed, paraffin-embedded tissues. J. Mol. Diagn. 2012, 14, 22-29. [CrossRef] [PubMed]

50. Player, A.N.; Shen, L.P.; Kenny, D.; Antao, V.P.; Kolberg, J.A. Single-copy gene detection using branched DNA (bDNA) in situ hybridization. J. Histochem. Cytochem. 2001, 49, 603-612. [CrossRef] [PubMed]

51. Westwood, F.R. The Female Rat Reproductive Cycle: A Practical Histological Guide to Staging. Toxicol. Pathol. 2008, 36, 375-384. [CrossRef] [PubMed] 